\title{
QUANTITATIVE HISTOCHEMISTRY OF THE NEPHRON. VI. HYDROXYPROLINE IN THE HUMAN GLOMERULUS *
}

\author{
SJOERD L. BONTING, $†$ HENDRINA DE BRUIN AND VICTOR E. POLLAK $\ddagger$
}

(From the Departments of Biological Chemistry and Medicine, University of Illinois College

of Medicine, and Departments of Medicine, Presbyterian-St. Luke's Hospital, Cook County Hospital and Research and Education Hospitals, Chicago, III.)

(Submitted for publication June 23, 1960; accepted August 11, 1960)

Staining reactions characteristic of collagen and reticulin are found in pathologically altered glomeruli $(1,2)$, and fibrils with the periodicity of collagen fibrils have been observed occasionally in electron micrographs of severely damaged glomerular tufts. However, as far as we are aware, fibrils have not been found by light or electron microscopy in the normal glomerular tuft, except at the hilus; and, in particular, no fibrils with the periodicity of collagen fibrils have been seen in the normal glomerular capillary basement membrane (3-6).

Hydroxyproline estimations are widely used as a measure of collagen because no other known animal protein contains appreciable amounts of this amino acid $(7,8)$. Goodman, Greenspon and Krakower used sonic vibration to separate glomerular basement membrane from healthy canine glomeruli and found that the hydroxyproline content of their basement membrane preparations was 7 per cent (9). They suggested, therefore, that glomerular capillary basement membrane contained a considerable amount of collagen. As their results appeared to conflict with the morphological evidence, the hydroxyproline content of the human glomerulus was reinvestigated, using a microdissection and microassay technique in which glomerular tufts were dissected out intact and free of Bowman's capsules for hydroxyproline assay.

\section{METHODS}

Portions of human kidney were obtained postmortem and were frozen rapidly in liquid nitrogen, as described

* Supported by a contract from the Surgeon General's Office, U. S. Army (Contract no. DA-49-007-MD-637), and by a grant from the U. S. Public Health Service, National Institutes of Health, Bethesda, Md. (H-3912).

$\uparrow$ Present address: Section on Cell Biology, National Institute of Neurological Diseases and Blindness, Bethesda, Md.

$\ddagger$ Established Investigator, American Heart Association, supported by the Illinois Heart Association. previously $(10,11)$. Sections were cut at $30 \mu$ in a cryostat, were mounted on glass slides and were then lyophilized at $-20^{\circ} \mathrm{C}$. From these lyophilized sections individual glomeruli were dissected out freehand under a dissecting microscope. The dissected glomerular tufts were free of Bowman's capsules. The glomeruli were pooled in groups of 12 to 20 , weighed on a quartz fiber balance, and inserted into micro-test tubes for chemical analysis. In addition, portions of arcuate arteries were dissected out and analyzed separately.

Hydroxyproline was measured by a modification of Grunbaum and Glick's ultra-micro adaptation (12) of the method of Neumann and Logan (13). Twenty $\mu 1$ of 6 $\mathrm{N} \mathrm{HCl}$ was added to the glomeruli contained in the microtest tubes, which were then sealed and heated at $170^{\circ} \mathrm{C}$ for 1 hour. They were opened and the hydrolysate was evaporated to dryness over $\mathrm{NaOH}$ pellets in a vacuum desiccator. Ten $\mu \mathrm{l}$ of $5 \mathrm{mM} \mathrm{CuSO}$ and $10 \mu \mathrm{l}$ of a freshly prepared mixture containing $1.25 \mathrm{M} \mathrm{NaOH}$, and 1 per cent $\mathrm{H}_{2} \mathrm{O}_{2}$ were added to each tube. The tubes were vibrated rapidly to stir the mixture, capped with parafilm, and heated at $75^{\circ} \mathrm{C}$ for 6 minutes. Next, $35 \mu \mathrm{l}$ of a freshly prepared mixture containing $1.71 \mathrm{M} \mathrm{H}_{2} \mathrm{SO}_{4}$ and 1.14 per cent $p$-dimethylaminobenzaldehyde was added. The tubes were again vibrated rapidly to mix, capped and heated at $75^{\circ} \mathrm{C}$ for 15 minutes. The optical density of the resulting solution was read at $557 \mathrm{~m} \mu$. The color was found to be stable for at least 1 hour when the tubes were kept in an ice bath after color formation. The hydroxyproline concentration in tissue samples was expressed as a percentage of the dry weight.

Suitable blanks and standards were carried through the entire procedure including hydrolysis. The standard curves obtained were linear up to optical densities of 0.350. A commercial dried gelatin preparation (Knox) was found to contain 12.0 per cent hydroxyproline. When hydroxyproline was added to the gelatin a recovery of 105.6 per cent was obtained (equivalent, within the experimental error, to 100 per cent).

\section{RESULTS}

The hydroxyproline concentration in glomeruli from seven healthy kidneys was measured (Table I). The patients had died of causes other than renal disease, and had had no clinical evidence of renal damage. Their kidneys were normal macroscopically and the glomeruli were within normal 
TABLE I

Hydroxyproline concentration in the glomeruli and arcuate arteries of human kidney (expressed as a percentage of dry weight $)^{*}$

\begin{tabular}{|c|c|}
\hline & $\begin{array}{c}\text { Hydroxyproline } \\
\text { concentration }\end{array}$ \\
\hline \multicolumn{2}{|l|}{ Normal human glomeruli } \\
\hline Infant ( 1 day) & $1.13 \underset{[5]}{ \pm 0.073}$ \\
\hline Infant (5 months) & $0.95 \underset{[3]}{ \pm} 0.101$ \\
\hline Male (25 yrs) & $1.11 \pm 0.080$ \\
\hline Female (26 yrs) & $1.20 \underset{[4]}{ \pm}$ \\
\hline Male (43 yrs) & $1.08 \underset{[4]}{ \pm 0.12}$ \\
\hline Male (65 yrs) & 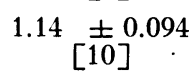 \\
\hline Male (84 yrs) & $1.15 \pm \underset{[9]}{0.059}$ \\
\hline Average & $1.109 \pm 0.030$ \\
\hline \multicolumn{2}{|l|}{ Abnormal human glomeruli } \\
\hline Adult Fanconi syndrome (51 yrs) & $1.57 \underset{ \pm 0}{ \pm 0.10}$ \\
\hline Nephrosclerosis (70 yrs) & $\begin{array}{cl} & 1.65 \\
& \pm 0.096 \\
{[3]}\end{array}$ \\
\hline Diabetic nephropathy (50 yrs) & $2.34 \pm 0.19$ \\
\hline \multicolumn{2}{|l|}{ Normal human arcuate arteries } \\
\hline Male (25 yrs) & $4.99 \underset{[3]}{ \pm} 0.65$ \\
\hline Female (26 yrs) & $\begin{array}{c}3.88 \pm 0.38 \\
{[4]}\end{array}$ \\
\hline Male (65 yrs) & $\begin{array}{l}4.19 \underset{[4]}{ \pm} 0.96 \\
\end{array}$ \\
\hline
\end{tabular}

* Results are expressed as the mean with the standard error and, in brackets, the number of determinations. Each determination was made on a pooled sample of approximately 20 glomeruli.

limits microscopically. The hydroxyproline concentration was found to be $1.109 \pm 0.030$ (standard error of the mean) per cent of the dry weight. This is equivalent to 8.9 per cent of collagen on the basis of a hydroxyproline concentration in collagen of 12.5 per cent (8). For comparison, the hydroxyproline concentration in renal arcuate arteries was measured and was found to be from 3.88 to 4.99 per cent of dry weight (Table I). This is equivalent to 31.0 to 39.9 per cent of collagen.

The hydroxyproline concentration in the glomeruli of three abnormal kidneys was also measured (Table I), and was found to be significantly increased in all. The highest hydroxyproline con- centration was found in the glomeruli of a patient with severe diffuse and nodular diabetic glomerulosclerosis. The hydroxyproline concentration was also increased in the glomeruli of a patient with moderately severe nephrosclerosis and diffuse thickening of the glomerular basement membrane, and in the glomeruli from a patient with multiple myeloma and the adult Fanconi syndrome.

\section{DISCUSSION}

The results indicate that there are significant amounts of hydroxyproline in the normal glomerulus. The hydroxyproline concentration in the glomeruli studied was remarkably constant from one individual to another, despite the wide range of the ages (from 1 day to 84 years) of the subjects studied; there was no increase of hydroxyproline concentration with increasing age. The glomerular basement membrane of man increases in thickness from birth (approximately $950 \AA$ ) to three years of age, when the adult thickness of $3,000 \AA$ is attained (14). If the hydroxyproline is located in the glomerular basement membrane, the hydroxyproline content of the whole glomerulus might be expected to increase from birth to three years of age. However, it must be remembered that all elements of the glomeruli increase in weight during growth. Elsewhere we have shown that the average dry weight of 130 healthy glomeruli dissected out from $16 \mu$ sections was 42.1 $\mathrm{m} \mu \mathrm{g}$ in the adult (15); that of 106 healthy glomeruli similarly dissected out from $16 \mu$ sections of kidney in infants ( 1 day to 5 months old) was $24.3 \mathrm{~m} \mu \mathrm{g}$. This resolves partially the apparent contradiction between our chemical findings and the electron microscopic observations. Another factor may be a difference in shrinkage for material from infants and adults during osmium tetroxide fixation, alcohol dehydration, and embedding for electron microscopy.

The proportion of hydroxyproline was increased in certain pathological conditions of the glomerulus characterized histologically by thickening of the capillary basement membrane and vascular sclerosis. This finding was consistent with histological studies of the abnormal glomeruli, using the Mallory azan technique, in which an increased amount of blue staining material, typical of collagen, was found. 
The only other reported chemical analysis of hydroxyproline in the glomerulus is that of Goodman and associates (9). These authors obtained glomeruli in bulk by screening and centrifugation of the renal cortex. From the isolated glomeruli, glomerular basement membrane was obtained by sonic vibration; it was analyzed for hydroxyproline (6.9 to 7.5 per cent), collagen ( 79.6 to 83.6 per cent), and total nitrogen (11.4 to 12.3 per cent). Thus, they recorded a hydroxyproline content in isolated glomerular basement membrane approximately 6.5 times higher than that found in the present investigation in whole glomeruli (without capsule).

The presence of endothelial and epithelial cells in glomeruli prepared according to our method and their absence from the preparations analyzed by Goodman and co-workers, partially explains the difference. However, the magnitude of the difference suggests that other factors may be important, such as solubilization of noncollagen protein during the isolation procedure used by these authors.

To elucidate this difference, whole glomeruli from a healthy male, aged 25 years (Table I), were analyzed for hydroxyproline: 1) after isolation by screening and centrifugation by the technique of Goodman and associates (9). followed by freeze-drying ( $3.23 \pm 0.21$ per cent $)$; and 2$)$ after dissection from frozen-dried sections $(1.11 \pm 0.08$ per cent). The threefold difference found in the two methods of preparation of the tissue for analysis is not likely to be due to the inclusion or omission of Bowman's capsules, since it has been shown that the hydroxyproline concentration in glomeruli is not significantly different, whether or not the glomeruli are dissected free of Bowman's capsules before analysis (9). It is explained most readily by solubilization of noncollagen protein during the wet isolation procedure. This view is supported by the ratio of collagen to total nitrogen in the experiments of Goodman and co-workers, which suggests that little or no noncollagen protein was present in the glomerular basement membrane preparations analyzed by them.

The absence of electron microscopic evidence of a fibrillar structure in the glomerular basement membrane might suggest that there is no collagen in this structure, and the demonstration of a hydroxyproline content of 1.109 per cent might ap- pear to be in conflict with the electron microscopic observations. This apparent contradiction can be reconciled by assuming that the basement membrane contains a nonfibrillar, hydroxyproline-rich protein. This view is consistent with the solubility and enzymatic digestibility of Greenspon, Bollinger and Krakower's basement membrane preparation (16).

Most electron microscopic studies of collagen have been made on material extracted from skin or tendon. Jackson has suggested that intracellular collagen is not fibrous and that it is excreted in this form into the extracellular spaces from which it can be extracted as a neutral salt-soluble collagen (17). Both he and Gross (18) have shown that neutral salt-soluble collagen has the consistency of a gel in vitro, which at times may polymerize or precipitate spontaneously into typical collagen fibrils. Moreover, neutral salt-soluble collagen appears to be a precursor in vivo of the form with $640 \AA$ banded fibrils (18). Thus, the electron microscopic observations and the biochemical findings reported here could be reconciled by assuming that the normal glomerular basement membrane contains a nonfibrillar form of collagen similar to the neutral salt-extractable, soluble collagen of Jackson and Gross $(17,18)$, and that the the fibrillar form is laid down only under pathological conditions.

\section{SUM M ARY}

1. The hydroxyproline concentration in glomerular tufts from nine healthy kidneys was measured, and was found to be 1.109 per cent of the dry weight. Its concentration was not related to the age of the subjects. In renal arcuate arteries the hydroxyproline concentration was 3.88 to 4.88 per cent of dry weight. In abnormal glomeruli from three subjects the hydroxyproline concentration was significantly higher than in normal glomeruli, the highest concentration being found in a case of diabetic nephropathy.

2. These findings indicate that collagen is present in the glomerular basement membranes. The absence of fibrils, which has been demonstrated by the electron microscope, suggests that the collagen is present in a form which is a precursor of that with $640 \AA$ banded fibrils, possibly neutral saltextractable collagen. 


\section{ACKNOWLEDGMENTS}

We would like to thank Dr. Cecil A. Krakower for isolating glomeruli from one patient by screening and centrifugation. We would also like to thank Drs. R. M. Kark, D. S. Jackson and H. R. Catchpole for critical reviews of the manuscript.

\section{REFERENCES}

1. Allen, A. C. The Kidney, Medical and Surgical Diseases. New York, Grune and Stratton, 1951.

2. Jones, D. B. Inflammatory and vascular disease of the glomerulus in Analytical Pathology. Treatises in the Perspective of Biology, Chemistry and Physics, A. C. Mellors, Ed. New York, Blakiston, 1957.

3. Rinehart, J. F., Farquhar, M. G., Jung, H. C., and Abul-Haj, S. K. The normal glomerulus and its basic reactions in disease. Amer. J. Path. 1953, 29, 21.

4. Hall, B. V. Further studies of the normal structure of the renal glomerulus in Proceedings of the Sixth Annual Conference on the Nephrotic Syndrome, J. Metcoff, Ed. New York, National Nephrosis Foundation, 1954, p. 1.

5. Pease, D. C. Fine structures of the kidney seen by electron microscopy. J. Histochem. Cytochem. 1955, 3, 295.

6. Mueller, C. B., Mason, A. D., Jr., and Stout, D. G. Anatomy of the glomerulus. Amer. J. Med. 1955, 18, 267.

7. Gross, J. Studies on the formation of collagen. I. Properties and fractionation of neutral salt extracts of normal guinea pig connective tissue. J. exp. Med. 1958, 107, 247.
8. Gustavson, K. H. The Chemistry and Reactivity of Collagen. New York, Academic Press, 1956.

9. Goodman, M., Greenspon, S. A., and Krakower, C. A. The antigenic composition of the various anatomic structures of the canine kidney. J. Immunol. 1955, 75, 96.

10. Bonting, S. L., Pollak, V. E., Muehrcke, R. C., and Kark, R. M. Quantitative histochemistry of the nephron. Science 1958, 127, 1342.

11. Bonting, S. L., Pollak, V. E., Muehrcke, R. C. and Kark, R. M. Quantitative histochemistry of the nephron. II. Alkaline phosphatase activity in man and other species. J. clin. Invest. 1960, 39, 1372.

12. Grunbaum, B. W., and Glick, D. Studies in histochemistry. XLV. Determination of hydroxyproline in microgram amounts of tissue. Arch. Biochem. 1956, 65, 260.

13. Neumann, R. E., and Logan, M. A. The determination of hydroxyproline. J. biol. Chem. 1950, 184, 299.

14. Vernier, R. L. Personal communication.

15. Pollak, V. E., Bonting, S. L., Muehrcke, R. C., and Kark, R. M. Quantitative histochemistry of the nephron. V. Alkaline phosphatase and lactic dehydrogenase activity in lupus nephritis. J. clin. Invest. 1960, 39, 1394.

16. Greenspon, S. A., Bollinger, F. W., and Krakower, C. A. Some chemical properties of nephrotoxic antigen. Fed. Proc. 1952, 11, 416.

17. Jackson, D. S. The formation and breakdown of connective tissue in Connective Tissue, R. E. Tunbridge, Ed. Oxford, Blackwells, 1957.

18. Gross, J. Studies on the fibrogenesis of collagen. Some properties of neutral extracts of connective tissue in Connective Tissue, R. E. Tunbridge, Ed. Oxford, Blackwells, 1957.

\section{CORRECTION}

On page 1597 of the paper entitled "Serum factors in lupus erythematosus and other diseases reacting with cell nuclei and nucleoprotein extracts : Electrophoretic, ultracentrifugal and chromatographic studies" by Howard C. Goodman, John L. Fahey and Richard A. Malmgren (J. clin. Invest. 1960, 39, 1595), lines 15-18 should read: "Anti-calf thymus nucleoprotein extract activity was present in 85 per cent of SLE sera, 10 per cent of the RA sera and 25 per cent of the scleroderma sera." An error in typesetting omitted a line which confused the meaning of this sentence. Also, on page 1600 of the same article, the first sentence at the top of column 2 should read: "The proteins eluted first are seen to sediment less rapidly $\left(\mathrm{s}^{0}{ }_{20, \mathrm{w}} \cong 6.6 \mathrm{~S}\right)$ than those eluted in the 60 to 80 per cent effluent region $\left(\mathrm{s}^{0}{ }_{20, \mathrm{w}} \cong 18 \mathrm{~S}\right)$." 